\title{
Metaphor: Bridging embodiment to abstraction
}

\author{
Anja Jamrozik $^{1} \cdot$ Marguerite McQuire $^{1} \cdot$ Eileen R. Cardillo $^{1} \cdot$ Anjan Chatterjee $^{1}$
}

Published online: 9 June 2016

(C) Psychonomic Society, Inc. 2015

\begin{abstract}
Embodied cognition accounts posit that concepts are grounded in our sensory and motor systems. An important challenge for these accounts is explaining how abstract concepts, which do not directly call upon sensory or motor information, can be informed by experience. We propose that metaphor is one important vehicle guiding the development and use of abstract concepts. Metaphors allow us to draw on concrete, familiar domains to acquire and reason about abstract concepts. Additionally, repeated metaphoric use drawing on particular aspects of concrete experience can result in the development of new abstract representations. These abstractions, which are derived from embodied experience but lack much of the sensorimotor information associated with it, can then be flexibly applied to understand new situations.
\end{abstract}

Keywords Metaphor - Abstract concepts · Abstraction . Embodiment $\cdot$ Grounded cognition

Embodied accounts of cognition (Barsalou, 2008; Fischer \& Zwaan, 2008; Gibbs, 2006a; Glenberg, 2010; Pecher \& Zwaan, 2005; M. Wilson, 2002) posit that cognitive processes are grounded in our sensorimotor systems. Many embodied cognition accounts stress the role of the simulation of sensory and motor experiences (e.g., Barsalou, 1999) when thinking of concepts of entities and actions (e.g., Glenberg \& Kaschak,

Anja Jamrozik

jamrozik@mail.med.upenn.edu; a.jamrozik@gmail.com

1 Department of Neurology, Center for Cognitive Neuroscience, University of Pennsylvania, Philadelphia, Pennsylvania, USA
2002; Zwaan \& Taylor, 2006). Embodied cognition, bolstered by the discovery of mirror neurons in the macaque and mirror neuron systems in humans (Rizzolatti \& Craighero, 2004), has become a dominant organizing framework in cognitive science. However, the success and popularity of embodied accounts invites an obvious question: If concepts are fundamentally grounded in sensory and motor experiences and are instantiated in the brain through our sensory and motor systems, how do humans abstract (Chatterjee, 2010; Dove, 2009; Mahon \& Caramazza, 2008)? In this article, we propose that the use of metaphors is one important means by which people abstract. Extending landmark work demonstrating that metaphors are integral to how we understand the world (e.g., Lakoff \& Johnson, 1980, 1999), we suggest that metaphors go beyond embodiment to deliver elements for abstract thought.

Abstract concepts do not directly call upon sensory or motor information. Many abstract concepts pick out relational patterns, in contrast to concrete concepts, which pick out entities that share common intrinsic properties - properties often cast in sensory and motor terms (e.g., Barr \& Caplan, 1987; Gentner \& Kurtz, 2005; Markman \& Stilwell, 2001; WiemerHastings \& $\mathrm{Xu}, 2005)$. How do we account for our ability to conceptualize such concrete entities as apple, dog, or chair, as well as abstract, relational ideas such as truth, reciprocity, or respect?

Metaphors allow us to draw on concrete, familiar knowledge to reason about abstract concepts (e.g., Gallese \& Lakoff, 2005; Gibbs, 1994, 2006a; Lakoff \& Johnson, 1980, 1999). For example, we use vertical spatial terms to talk about positive and negative emotional valence (e.g., "she was feeling up"; e.g., Casasanto \& Dijkstra, 2010; Lakoff \& Johnson, 1980, 1999; Meier \& Robinson, 2004), or talk about relationships in terms of physical journeys (e.g., "they're at a crossroads"; Lakoff \& Johnson, 1980, 1999). How are these 
concrete-abstract relations learned, and what are the consequences of this learning for embodied accounts? In the first section, we describe how metaphors can be used to extend our thinking and elaborate on the relation of embodied views and metaphor. The following two sections present behavioral and neural evidence that ultimately leads us to suggest that metaphors use embodiment to catapult our thinking into abstraction.

\section{Metaphor}

Metaphors in nominal sentences (e,g., $X$ is a $Y$ ) are made up of two parts: a target, which is the topic of the statement, and a base, which provides information about the target. For example, in the metaphor "negotiation is a tool," negotiation is the target and tool is the base. Metaphors allow people to apply their knowledge of the base, which is typically more concrete and familiar, to inform their understanding of the less-familiar target (e.g., Gibbs, 1994; Kövecses, 1986, 2005; Lakoff \& Johnson, 1980, 1999; Lakoff \& Turner, 1989; Sweetser, 1990). For example, if someone is learning about the concept negotiation, the metaphor "negotiation is a tool" enables him or her to infer that, like a tool, negotiation can be used to achieve a goal, and that its use is specific to certain situations. In contrast, the metaphor "negotiation is an art form" would highlight the role of skill and expertise involved in negotiations.

Someone's representation of the metaphor target can be quite sparse before being elaborated by drawing on knowledge of the base. However, an independent representation of the target concept may be necessary in order to map onto it from a base concept (Murphy, 1996, 1997). In other words, it is not possible to map knowledge onto a nonexistent concept. This raises the question of how metaphors can support the acquisition of new abstract concepts. We remain agnostic about the initial genesis of abstract concepts, but suggest that they begin as underspecified placeholders before the representations are elaborated by drawing on one or more concrete base domains. As the target concept representation is built up through multiple metaphoric mappings, the representation becomes more abstract, even as it becomes more specified, retaining only those relational patterns and sensorimotor features common across the mappings. We elaborate on how this process might occur later in the article.

The meaning of the base in a metaphoric context extends beyond the term's concrete sense. In the metaphor "negotiation is a tool," the meaning of tool in context might be something like an entity that can be used to amplify a person's ability to accomplish a social goal, which is distinguished from the term's basic sense - a handheld instrument that allows people to carry out a particular physical function. Of course, the base term may have several senses, some more abstract than the most basic, concrete sense.

Nominal metaphors (e.g., "my lawyer is a shark") in which the base and target are explicitly stated have received the most attention (e.g., Bowdle \& Gentner, 2005; Glucksberg \& Keysar, 1990; Glucksberg \& McGlone, 2001; Ortony, 1979, 1993). Accounts of nominal metaphor comprehension generally propose that understanding involves comparison of the base and target (i.e., sharks and lawyers; e.g., M. G. Johnson \& Malgady, 1979; Miller, 1979; Ortony, 1979; Tversky, 1977) or categorization of the target as a member of a category represented by the base (i.e., aggressive, predatory creatures; e.g., Glucksberg, 2001; Glucksberg \& Keysar, 1990; Glucksberg, McGlone, \& Manfredi, 1997; Honeck, Kibler, \& Firment, 1987; A. T. Johnson, 1996).

More recently, the career-of-metaphor account (Bowdle \& Gentner, 2005; Gentner \& Bowdle, 2001; Gentner, Bowdle, Wolff, \& Boronat, 2001; Gentner \& Wolff, 1997, 2000; Wolff \& Gentner, 2011), an extension of structure-mapping theory (Gentner, 1983) to metaphor, has attempted to reconcile these views. According to structure-mapping, metaphors, like analogies, align the base and target, and then project inferences from the base to the target (e.g., Falkenhainer, Forbus, \& Gentner, 1989; Gentner, 1983, 1989; Gentner \& Markman, 1997; Markman \& Gentner, 1993). According to this account, the mode of metaphor mapping shifts from comparison to categorization as a metaphor becomes conventional.

Metaphors can be distinguished on the basis of the kind of alignment that holds between the base and target (Gentner \& Clement, 1988). In attributive metaphors, the base and target share object attributes. For example, in the metaphor "the sun is a tangerine," the base and target share the same shape and color. Relational metaphors are ones in which the base and target share relations or systems of relations. For example, in the metaphor "the mind is a kitchen," the base and target share the same relation to another entity (the place in which a meal or an idea is constructed over time). When aligning the representations of a metaphor's base and target, the goal is to find the maximal structurally consistent alignment (Falkenhainer et al., 1989; Gentner \& Markman, 1997; Markman \& Gentner, 1993). According to the systematicity principle (Clement \& Gentner, 1991; Gentner, 1983), there is a bias for deeper alignments, ones in which lower-order matches, such as those between objects, are connected by higher-order relations. All else being equal, matches based on larger, deeper relational systems, such as the ones shared by the base and target in relational metaphors, are preferred over shallow matches, such as the concrete properties shared by the base and target in attributive metaphors.

In addition to alignment type, metaphors vary by the word class of the base. Although most work on metaphor has examined noun-based, nominal metaphors, other types of word classes are frequently extended metaphorically, including 
verbs ("Mary ran for office"), prepositions ("Lucy is in love"), and adjectives ("Jane has a sweet heart"; e.g., Cameron, 2003; Steen et al., 2010). As is the case for nominal metaphors, the meaning of these metaphors' base terms in context extends beyond their basic, concrete sense(s). Some accounts have suggested that noun- and verb-based metaphors are processed in the same way (e.g., Torreano, Cacciari, \& Glucksberg, 2005), whereas other accounts have suggested different processes (e.g., Chen, Widick, \& Chatterjee, 2008). Given this uncertainty, we will examine whether noun and verb metaphors result in abstraction through the same or through different processes.

\section{Metaphor and embodiment}

Two possible embodied cognition views might account for how metaphor use can promote abstraction. Under a stronger embodied view (e.g., Gallese \& Lakoff, 2005; Gibbs, 2006b; Gibbs, Costa Lima, \& Francozo, 2004; N. L. Wilson \& Gibbs, 2007), metaphor comprehension, like literal language comprehension, relies on sensorimotor simulation. In order to understand a metaphor such as "negotiation is a tool," we simulate what we know about the base concept tool, drawing on past situations in which tools have been used, and then use that knowledge to map onto the abstract target concept negotiation. This view predicts that using a metaphor activates the sensorimotor systems typically associated with experiencing the base concept in the metaphor. Using a metaphor whose base involves a spatial dimension (e.g., "he's feeling down") should activate sensory systems related to processing space. Using a metaphor whose base names a manner of movement (e.g., "run for office") should activate the motor or the visual motion system. Using a metaphor whose base involves gustatory information (e.g., "sweet compliment") should activate the gustatory system. This activation should occur even for conventional metaphors, since processing the meaning of the base term requires sensorimotor simulation.

Some versions of this account (e.g., Barsalou, 1999), have proposed that extremely familiar metaphors could use polysemy - that is, that the base could be interpreted directly by drawing on an existing word sense. For example, if the verb explode is often used in the context of describing emotion, then the conventional metaphor "John exploded with anger" might activate a simulation of angry behavior instead of a simulation of physical explosions. However, this account has not explained how these abstract word meanings are acquired in the first place.

Under a weaker embodied account (e.g., Boroditsky, 2000; Boroditsky \& Ramscar, 2002; Chatterjee, 2010; Wolff \& Gentner, 2011), comprehending novel metaphors draws on sensorimotor information about the base, but the representation of the base can become abstracted through repeated metaphoric use. ${ }^{1}$ The career-of-metaphor account (Bowdle \& Gentner, 2005; Gentner \& Bowdle, 2001; Gentner \& Wolff, 1997, 2000) offers a possible explanation for how repeated metaphoric use results in abstraction. According to this view, novel metaphors are understood by aligning the representations of the target and the base. This alignment highlights any structure that the representations share, with relational commonalities being preferred over surface ones. For example, for the novel metaphor "negotiation is a muscle," aligning the representations of the base and target identifies what the two have in common (e.g., both enhance with training). If the same abstraction is derived from multiple alignments between a base and the target(s), it can be crystalized and stored as a new sense of the base term. For example, if after encountering "negotiation is a muscle," someone encountered other metaphors that made mappings with similar structural alignments, such as "reading is a muscle," "concentration is a muscle," "small talk is a muscle," and so forth, the person could then store the abstraction (i.e., an attribute that enhances with practice) as an additional (and salient, if used often enough) sense of the term muscle.

Two important characteristics derive from the metaphorical abstraction process: relational highlighting and sensorimotor shedding. When two representations are aligned, the alignment process favors deeper relational matches over shallow, surface-based matches (Clement \& Gentner, 1991). People prefer relational metaphors to attributive metaphors (Gentner \& Clement, 1988; Zharikov \& Gentner, 2002), and relational similarity is correlated with aptness (Gentner \& Clement, 1988). Therefore, people may be more likely to repeat metaphors with deep relational matches, since these metaphors are apt and revealing. Over time, only those sensorimotor properties of the base that were repeatedly drawn on in metaphoric mappings will remain salient, whereas the rest are shed.

So far, we have focused on abstraction that results from repeated alignments between a base and different targets. This account can also be extended to explain how a novel abstract target concept can be built up by drawing on multiple concrete base domains. We suggest that abstract concepts begin as underspecified placeholders whose representations are subsequently built up, among other ways, through metaphoric mappings. For example, a learner might hear a novel word and identify the word as being abstract on the basis of cues such as word length and inflection (e.g., identifying the word independence as abstract because it is long and inflected; Reilly, Westbury, Kean, \& Peelle, 2012). The learner could then create an underspecified representation of the concept

\footnotetext{
${ }^{1}$ This idea can be contrasted with previous proposals that repeated metaphoric use can result in conventionalized schemas (e.g., the container schema - "I've had a full life," "there are good ideas in your argument") and conventional correspondences between domains (e.g., space to time), but not abstraction of the metaphoric base (Lakoff \& Johnson, 1980).
} 
that contained any information that could be gleaned from the word's contexts. Metaphors would allow the learner to build up and constrain this initial representation. The first metaphoric mapping from a concrete base domain to the target could be used to project inferences about the target. Subsequent metaphoric mappings would result in further inferences and act to constrain the representation. The relational patterns and sensorimotor properties common to the many metaphoric mappings between the target and the different bases would then be integrated into the full representation of the target. If the base domains are quite diverse (e.g., space, taste, visual motion), the resulting target representation would likely be sparse in sensorimotor detail but rich in relational information-the hallmarks of an abstract concept.

This idea differs from some previous accounts (e.g., Gibbs, 1994; Lakoff, 1987; Lakoff \& Johnson, 1980), which have proposed that abstract concepts are represented in terms of concrete domains (i.e., that there is no independent representation of abstract concepts). According to the present account, knowledge drawn from concrete bases is used to build up the representation of an abstract concept that can then be used without drawing on the concrete domains that informed it.

As we outlined earlier, in addition to noun metaphors, verbs, prepositions, and adjectives are also frequently used figuratively. How would abstraction occur for these types of metaphors? By way of illustration, we consider verb metaphors. Relatively few accounts have been put forward to explain how verb metaphors are understood (e.g., Chen et al., 2008; Frisson \& Pickering, 2001; Torreano et al., 2005). According to Chen et al.'s (2008) account, verbs have sensorimotor features as well as more abstract features, and metaphorical uses of verbs are understood by highlighting those features that are in accordance with the verbs' linguistic context (e.g., the nouns it is paired with). This idea is consistent with evidence that if the noun does not fit the selectional restrictions of the verb, as occurs in metaphor, the meaning of the verb adjusts more than the meaning of the noun (Gentner \& France, 1988).

The spatial and motion features of an action named by a verb are likely to hold only for typical agents and patients of that action. For example, the action named by the verb gallop involves four legs being off the ground at the same time if the agent has four legs. If a person is galloping, that sensorimotor feature no longer holds. If a verb's meaning adjusts depending on the nouns with which it is paired, then if it is paired with an atypical agent or patient, the sensorimotor features incompatible with the noun pairing will not be incorporated into its meaning. In contrast, verbs maintain their relational meanings even when paired with atypical agents or patients. For example, the verb clean conveys removing a mess. This relational meaning applies with a typical agent (Sal cleaned the floor), and is retained with an atypical agent (the software cleaned the hard drive).
If a verb is extended metaphorically in a novel way-for example, in the metaphor "the emails galloped into her phone" - the sentence is understood by using the linguistic context to adjust the meaning of the verb. If that particular meaning of the verb (e.g., gallop meaning "entering quickly and dramatically") were repeated frequently enough (e.g., "new clients galloped into the organization," "problems galloped into their marriage," etc.), that meaning would be highlighted and would become a salient sense of the verb. This new sense retains the verb's relational meaning, and even retains some sense of speed, but lacks much of the verb's concrete sensorimotor associations, such as the specific manner of motion involved in the movement of limbs.

Regardless of whether nouns or verbs are used figuratively, there are advantages to deriving a metaphoric abstraction instead of repeatedly drawing on a full representation of the metaphoric base. As compared to the metaphoric base, the abstraction is more productive and flexible. Since the abstraction is confined by fewer surface (sensorimotor) features, it can be aligned with new targets more easily, because the alignment does not involve matching many surface features. Learning the abstraction and its applications in new contexts provides a powerful heuristic by which new abstract ideas can be formulated from and informed by old concrete experiences.

\section{Embodiment and behavioral studies of metaphor}

Metaphors frame our thinking. They help us reason about unfamiliar abstract domains and influence our representation of those domains. For example, Thibodeau and Boroditsky (2011) found that metaphors affected the conceptualization of crime. If crime was described as a "beast preying on" a fictional town, people recommended catching and imprisoning criminals. Alternatively, if crime was described as a "virus infecting" the town, people were more likely to recommend investigating its causes and "inoculating" the community. The base of the metaphor framed how people thought about the problem and the solutions they favored. Similarly, metaphor allows people to reason about the abstract domain of time by drawing on the more familiar and readily observable domain of spatial movement. Physical movement in space (whether real or imagined) has been found to influence the conceptualization of time (Boroditsky, 2000; Boroditsky \& Ramscar, 2002). Along with work demonstrating other cross-domain mappings from concrete to more abstract domains (e.g., Ackerman, Nocera, \& Bargh, 2010; Chiao et al., 2009; Meier \& Robinson, 2004), the results from these studies are evidence that our understanding of the physical world can shape our representations and reasoning about abstract concepts. 
According to the embodiment views outlined earlier, metaphor comprehension draws initially on sensorimotor experience. In line with this view, physical movement can facilitate metaphor comprehension. N. L. Wilson and Gibbs (2007) found that people were faster to assess whether or not a sentence was meaningful if they had performed (or imagined performing) a congruent motion before reading a metaphor (e.g., a grasping motion before reading "grasp a concept"), suggesting that comprehension of the metaphorical term grasp draws from simulation of its literal meaning. Further evidence has come from Richardson, Spivey, Barsalou, and McRae (2003), who found that readers simulate horizontal and vertical paths that are implied by both concrete and abstract verbs (e.g., push vs. lift, argue vs. respect). The spatial orientation implied by the verb affected later performance on a visual discrimination task and on the encoding of a visual memory.

According to a strong embodiment view, metaphor comprehension relies on automatic and obligatory sensorimotor simulation. Such comprehension might become faster or more efficient with increased experience with a particular metaphorical mapping, but it will not be eliminated even for conventional metaphorical uses. According to a weaker embodiment view, repeated metaphoric use should result in abstraction. In line with the weaker view, there is linguistic support for the idea that the mode of metaphor processing shifts over the course of familiarization. When people encounter a novel mapping between a target and a base, they prefer that it be expressed in simile form (e.g., an obsession is like a tumor vs. an obsession is a tumor), which makes explicit the comparison involved (Bowdle \& Gentner, 2005). However, after repeatedly encountering similar mappings between a base and different targets (e.g., "doubt is like a tumor," "a grudge is like a tumor"), their preference for the metaphor form ("an obsession is a tumor") increases (Bowdle \& Gentner, 2005). This shift in preference suggests that an explicit comparison between the base and targets becomes less necessary over the course of familiarization. Instead, people align new targets with the metaphoric abstraction derived from the mappings, and categorize them as members of an abstract category now exemplified by the base.

Both the strong and weak embodiment views predict that familiarization should increase the speed of metaphor comprehension. In line with this prediction, conventional metaphors are processed faster than novel ones (Blank, 1988; Bowdle \& Gentner, 2005; Gentner \& Wolff, 1997). Under a strong embodiment view, this is because of improved speed or efficiency of simulation. Under a weaker view, this is because aligning a target with a metaphoric abstraction is less computationally costly than aligning a target with a novel metaphoric base. Once a metaphor is familiar (e.g., "loneliness is a desert") and the base term (desert) has been used frequently enough to become polysemous, the base simultaneously activates a literal concept (a sandy, hot place) and an abstract category (void of people) (Gentner \& Wolff, 1997). Using a cross-modal priming experiment, Blasko and Connine (1993) showed that metaphoric and literal meanings are both equally accessible, but only for metaphors that are highly familiar (or highly apt). Neural studies, as we will discuss below, might offer methods that could adjudicate between strong and weak embodied accounts that are not distinguished easily by behavioral methods alone.

The abstract metaphoric meaning of a base term may be accessed even before its literal meaning. Giora (1997, 1999, 2003) proposed that most words have multiple meanings that vary in their salience. A metaphorical meaning that is highly salient can be accessed first, and the metaphor will be understood rapidly. When this meaning is not salient, it will be understood more slowly. Glucksberg, Newsome, and Goldvarg (2001) suggested that a base term's metaphoric meaning can become salient through context or priming. They asked people first to read a metaphor (e.g., "my lawyer is a shark") and then to verify literal statements about the base (shark). Metaphor priming inhibited access to the information associated with the literal meaning of the base (e.g., sharks are good swimmers), leading to significantly longer response times than when people were primed with literal statements (e.g., "hammerhead is a species of shark"). In a similar study, Glucksberg, McGlone, and Manfredi (1997) found that priming an attribute of the literal meaning of a base interfered with access to its metaphorical meaning. The metaphorical meaning of a word or phrase can become its default, most salient meaning given the right context, through priming or through repeated exposure.

If repeated frequently enough, metaphorical meanings become conventionalized within a language, resulting in polysemy (e.g., Gibbs, 1994; Glucksberg \& Keysar, 1990; Lehrer, 1990; Miller, 1979; Sweetser, 1990). Metaphors can also lead to a shift in word meaning over time. For example, spatial terms have come to have dominant temporal meanings through metaphoric extension (e.g., Heine, 1997; Traugott, 1978), and words related to sensory perception to have meanings related to mental activity (e.g., "I see that point"; Sweetser, 1990).

Historically, abstract, figurative meanings appear later than the literal meaning in written language (Zharikov \& Gentner, 2002). The literal meaning of the word sanctuary (i.e., a holy building), for example, first appeared in text in 1340. By 1685, however, the same word was also used figuratively to mean a safe space (Zharikov \& Gentner, 2002). Together, these findings support the idea that repeated metaphoric uses result in abstractions that are stored as additional word senses, both for individual people and for a population of speakers of a language. 


\section{Embodiment and neural studies of metaphor}

According to a strong embodiment view, simulation is both automatic and necessary for understanding language, with conceptual access requiring reactivation of the sensorimotor activity needed for a concept's perception and execution. Under this view, even abstract ideas are understood through concrete concepts, and thus are mediated by the same sensorimotor simulations and neural structures (e.g., Gallese \& Lakoff, 2005; Gibbs, 2006b; Gibbs, Costa Lima, \& Francozo, 2004; N. L. Wilson \& Gibbs, 2007). In the case of action verbs, for instance, both literal and figurative usages are predicted to rely on motor areas. In support of this view, words referring to literal actions by specific body parts appear to engage motor/ premotor cortex, and in a manner loosely consistent with the somatotopic organization of these regions (Hauk, Johnsrude, \& Pulvermüller, 2004; Kemmerer, Castillo, Talavage, Patterson, \& Wiley, 2008; Tettamanti et al., 2005). Evidence for semantic somatotopy in the case of figurative uses of action words, however, is mixed. Some studies have indicated somatotopic activation in motor areas when participants read both literal ("John grasped the object") and idiomatic ("John grasped the idea") uses of action verbs (Boulenger, Hauk, \& Pulvermüller, 2009; Boulenger, Shtyrov, \& Pulvermüller, 2012), whereas others have observed motor activation only for literal, but not for idiomatic, senses (Aziz-Zadeh, Wilson, Rizzolatti, \& Iacoboni, 2006; Raposo, Moss, Stamatakis, \& Tyler, 2009).

These mixed results are further challenged by the larger literature on action-verb processing, which does not indicate consistent motor activation even in literal usage (for a recent meta-analysis, see Watson, Cardillo, Ianni, \& Chatterjee, 2013). These discrepancies suggest that motor engagement may depend on the task, context, participant experience with the actions, or some combination of these factors. Furthermore, our experience with actions entails their observation as well as their execution, suggesting a role for perceptual and not just motor simulations in understanding action words, even within an embodiment framework.

This more broadly construed embodied hypothesis has been tested in several recent investigations of literal and figurative extensions of verbs with salient motion features. Of critical interest is whether motion words activate area MT+, primary cortex for visual motion perception (Tootell et al., 1995), and adjacent secondary areas including posterior middle temporal gyrus (pMTG), an area responsive to words with motion associations (Kable, Kan, Wilson, Thompson-Schill, \& Chatterjee, 2005; Kable, Lease-Spellmeyer, \& Chatterjee, 2002). Consistent with embodiment predictions, motionsensitive cortex is more strongly activated when reading about literal motion rather than non-motion (Humphreys, Newling, Jennings, \& Gennari, 2013; Wallentin et al., 2011), and when reading sentences with figurative extensions of motion verbs, whether they are used metaphorically ("The man fell under her spell"; Chen et al., 2008) or to convey fictive motion ("The pipe goes into the house"; Saygin, McCullough, Alac, \& Emmorey, 2010; Wallentin, Lund, Östergaard, Östergaard, \& Roepstorff, 2005; Wallentin, Östergaard, Lund, Östergaard, \& Roepstorff, 2005). Notably, in all but one of these studies (Saygin et al., 2010), motion verbs did not engage primary motion perception cortex, MT + , but instead neighboring cortex, such as pMTG. ${ }^{2}$ According to a strong embodiment view, which posits automatic and obligatory simulation, we would expect to see primary sensorimotor activation for both literal and figurative motion verb uses. The pattern of results is not consistent with this view. Instead, figurative uses seem to engage secondary areas anterior to primary motion cortex, which may process more abstracted conceptual representations of motion (Chatterjee, 2008), consistent with a weaker version of the embodiment hypothesis.

Although most fMRI studies of embodiment have focused on motion verbs, embodied accounts predict sensory engagement for whatever modality is most salient to a word's meaning. Citron and Goldberg (2014) considered the domain of taste, observing greater recruitment of both primary and secondary gustatory areas for taste as compared to nontaste words, and for metaphoric as compared to literal senses of taste words ("She received a sweet/nice compliment"). Lacey, Stilla, and Sathian (2012) considered the domain of texture, observing greater recruitment of some, but not all, non-primary texture-selective sensory regions for metaphoric relative to literal senses of texture words ("She had a rough/bad day"). The inconsistent recruitment of primary sensorimotor areas argues against claims of obligatory and automatic simulations, suggesting instead that secondary association cortices may be sufficient for representing linguistically coded concepts. Importantly, most of the reviewed studies have relied on reverse inference to assign sensorimotor functions to activated regions or have used anatomically defined regions of interest. To more vigorously test embodied hypotheses, studies would need to examine activation within areas defined by sensory and motor functional localizers.

Thus, neuroimaging has provided substantial evidence for the sensorimotor grounding of metaphors, but has only partially supported strong claims for obligatory reactivation of the same neural processes required for perception and action. We suggest, in agreement with others (Aziz-Zadeh \& Damasio, 2008; Cardillo, Schmidt, Kranjec, \& Chatterjee, 2010; Desai, Binder, \& Conant, 2011), that the mixed support for primary sensorimotor cortex reactivation underscores the importance of metaphor diversity. The strength of

\footnotetext{
${ }^{2}$ One possible reason for the differences in results across studies may be the variability of MT+ locations across people. Only the Humphreys et al. (2013) and Saygin et al. (2010) studies used MT+ functional localizers. The discrepancy in findings across studies underscores the importance of including functional localizers to identify regions of interest.
} 
sensorimotor features in a particular word use (e.g., Lebois, Wilson-Mendenhall, \& Barsalou, 2014; Zwaan \& Taylor, 2006) and participants' familiarity with a more abstract sense (e.g., Giora, 1997, 1999; Mashal, Faust, Hendler, \& JungBeeman, 2007) may be strong modulators of cognitive and neural processing. Consistent with this view, Desai et al. (2011) observed comparable activation of secondary sensorimotor areas associated with action planning and coordination for literal and metaphoric sentences of arm/hand action verbs, whereas activity in primary motor areas was negatively correlated with familiarity in both conditions (see also Obert et al., 2014). This result suggests that failures to observe motor cortex engagement in previous studies (Aziz-Zadeh et al., 2006; Raposo et al., 2009) occurred because highly conventional, idiomatic sentences were tested. Sensorimotor features were irrelevant to the idiomatic senses of the verbs, which have been sufficiently overlearned to become lexicalized, obviating the need to extrapolate from a simulation of the literal sense. A novel sense, however, requires online abstraction, a process entailing initial activation of a word's literal sense via sensorimotor simulation and subsequent, rapid selection and integration only of those features aligned to create the metaphorical meaning. With repeated exposure to a novel metaphor, people learn and store the abstraction as another sense of the metaphor base. They can then resolve the meaning of a subsequently encountered metaphor with the same base term by drawing on this abstraction instead of by simulating the base's literal sense. Therefore, the strength of sensorimotor engagement in metaphor may reflect the degree of experience that people have with deriving a metaphoric abstraction (Cardillo, Watson, Schmidt, Kranjec, \& Chatterjee, 2013).

According to a weaker embodiment view, a metaphor's sensorimotor grounding will also vary depending on the strength of sensorimotor features in the metaphoric abstraction. For example, attributive metaphors ("the sun is a tangerine") should result in metaphoric abstractions that retain more sensorimotor features than do relational metaphors ("the mind is a kitchen"). The same view can be extended to other figurative uses, such as fictive motion, which should retain some sensorimotor features of literal motion, and idiomatic uses, which should retain few, if any, sensorimotor features.

Studies directly comparing figurative expressions varying in the strength of sensorimotor features support this graded view. For instance, a comparison of literal, metaphoric, and idiomatic uses of action verbs to abstract sentences has indicated sensorimotor grounding in a secondary actionprocessing area (anterior inferior parietal lobule) for literal and metaphoric but not for idiomatic senses, and a linear trend paralleling the verb uses degrees of sensorimotor abstraction (i.e., literal > metaphoric > idiomatic > abstract; Desai, Conant, Binder, Park, \& Seidenberg, 2013). Similar graded observations have been made in fMRI and transcranial magnetic stimulation (TMS) studies comparing literal, fictive, metaphoric, and idiomatic extensions of motion verbs (Cacciari et al., 2011; Romero Lauro, Mattavelli, Papagno, \& Tettamanti, 2013).

Taken together, we argue that neural studies of metaphor comprehension support weak embodiment accounts, in which sensorimotor grounding is most likely when the sensorimotor features of a word are especially relevant for comprehension (as when encountering novel metaphoric uses), but is otherwise optional or epiphenomenal. Furthermore, the degree of sensorimotor grounding is graded by the strength of sensorimotor features in abstracted senses and by our experience with those abstractions. We predict that less familiar and less abstract senses will be more strongly grounded in modalityspecific cortex, and that the processing of more familiar and more abstract senses will be neurally shifted toward perisylvian language areas. However, it remains to be seen whether sensorimotor engagement is ever necessary for comprehension. To convincingly argue against an epiphenomenal or facilitatory interpretation, patient or virtual lesion (i.e., TMS) investigations demonstrating that the inability to draw upon relevant sensorimotor cortices impairs comprehension would be needed. ${ }^{3}$ However, our main point and prediction remains that if repeated metaphor use is a vehicle by which humans abstract, then the comprehension of metaphors over time should become less likely to be grounded in sensorimotor cortices.

\section{Conclusions}

Embodiment accounts have become a dominant frame for thinking about cognitive processes. However, such accounts face an obvious question: If cognition is grounded in sensory and motor systems, how do humans escape this grounding to engage in abstract thoughts and think relationally? We suggest that metaphor is one vehicle that guides the development and use of abstract concepts. Repeatedly drawing on particular aspects of concrete entities and events in order to highlight their abstract relational properties extends our conceptual reach beyond the grounding provided by sensorimotor systems. These abstract representations can be flexibly applied to new situations and serve as a powerful heuristic to understand new situations using the relational lessons learned from old ones.

\footnotetext{
${ }^{3}$ Some initial evidence suggesting that a form of motor engagement may be necessary for figurative language comprehension has come from a study showing that Parkinson's patients were impaired (slower) in understanding literal action sentences ("The sailor pulled the rope around the mast") and idiomatic action sentences ("The bank pulled the plug on the deal"), but not sentences that involved abstract verbs ("The violent film changed all of his ideas"), as compared to control participants (Fernardino et al., 2013). However, even this study implicated impairments of higherorder motor control circuits instantiated through the basal ganglia, rather than primary motor outflow.
} 
Author note This work was supported by NIH Grant Number RO1 DC012511 and by a subcontract under NSF Grant Number SBE0541957.

\section{References}

Ackerman, J. M., Nocera, C. C., \& Bargh, J. A. (2010). Incidental haptic sensations influence social judgments and decisions. Science, 328, 1712-1715. doi:10.1126/science.1189993

Aziz-Zadeh, L., \& Damasio, A. (2008). Embodied semantics for actions: Findings from functional brain imaging. Journal of Physiology, 102, $35-39$.

Aziz-Zadeh, L., Wilson, S. M., Rizzolatti, G., \& Iacoboni, M. (2006). Congruent embodied representations for visually presented actions and linguistic phrases describing actions. Current Biology, 16, 1818-1823. doi:10.1016/j.cub.2006.07.060

Barr, R. A., \& Caplan, L. J. (1987). Category representations and their implications for category structure. Memory \& Cognition, 15, 397418.

Barsalou, L. W. (1999). Perceptual symbol systems. Behavior and Brain Sciences, 22, 577-609. doi:10.1017/S0140525X99002149. disc. 609-660.

Barsalou, L. W. (2008). Grounded cognition. Annual Review of Psychology, 59, 617-645. doi:10.1146/annurev.psych.59.103006. 093639

Blank, G. D. (1988). Metaphors in the lexicon. Metaphor and Symbol, 3, 21-36.

Blasko, D. G., \& Connine, C. M. (1993). Effects of familiarity and aptness on metaphor processing. Journal of experimental psychology: Learning, memory, and cognition, 19, 295.

Boroditsky, L. (2000). Metaphoric structuring: Understanding time through spatial metaphors. Cognition, 75, 1-27.

Boroditsky, L., \& Ramscar, M. (2002). The roles of body and mind in abstract thought. Psychological Science, 13, 185-189. doi:10.1111/ 1467-9280.00434

Boulenger, V., Hauk, O., \& Pulvermüller, F. (2009). Grasping ideas with the motor system: Semantic somatotopy in idiom comprehension. Cerebral Cortex, 19, 1905-1914.

Boulenger, V., Shtyrov, Y., \& Pulvermüller, F. (2012). When do you grasp the idea? MEG evidence for instantaneous idiom understanding. NeuroImage, 59, 3502-3513.

Bowdle, B., \& Gentner, D. (2005). The career of metaphor. Psychological Review, 112, 193-216.

Cacciari, C., Bolognini, N., Senna, I., Pellicciari, M. C., Miniussi, C., \& Papagno, C. (2011). Literal, fictive and metaphorical motion sentences preserve the motion component of the verb: ATMS study. Brain and Language, 119, 149-157.

Cameron, L. (2003). Metaphor in educational discourse. New York: Continuum.

Cardillo, E. R., Schmidt, G. L., Kranjec, A., \& Chatterjee, A. (2010). Stimulus design is an obstacle course: 560 matched literal and metaphorical sentences for testing neural hypotheses about metaphor. Behavior Research Methods, 42, 651-664. doi:10.3758/BRM. 42.3.651

Cardillo, E. R., Watson, C. E., Schmidt, G. L., Kranjec, A., \& Chatterjee, A. (2013). From novel to familiar : Tuning the brain for metaphors. NeuroImage, 59, 3212-3221.

Casasanto, D., \& Dijkstra, K. (2010). Motor action and emotional memory. Cognition, 115, 179-185. doi:10.1016/j.cognition.2009.11.002

Chatterjee, A. (2008). The neural organization of spatial thought and language. Seminars in Speech and Language, 29, 226-238.

Chatterjee, A. (2010). Disembodying cognition. Language and Cognition, 2, 79-116. doi:10.1515/LANGCOG.2010.004
Chen, E., Widick, P., \& Chatterjee, A. (2008). Functional-anatomical organization of predicate metaphor processing. Brain and Language, 107, 194-202.

Chiao, J. Y., Harada, T., Oby, E. R., Li, Z., Parrish, T., \& Bridge, D. J. (2009). Neural representations of social status hierarchy in human inferior parietal cortex. Neuropsychologia, 47, 354-363.

Citron, F. M. M., \& Goldberg, A. E. (2014). Metaphorical sentences are more emotionally engaging than their literal counterparts. Journal of Cognitive Neuroscience, 26, 2585-2595.

Clement, C. A., \& Gentner, D. (1991). Systematicity as a selection constraint in analogical mapping. Cognitive Science, 15, 89-132.

Desai, R., Binder, J., \& Conant, L. (2011). The neural career of sensorymotor metaphors. Journal of Cognitive Neuroscience, 23, 23762386.

Desai, R. H., Conant, L. L., Binder, J. R., Park, H., \& Seidenberg, M. S. (2013). A piece of the action: modulation of sensory-motor regions by action idioms and metaphors. NeuroImage, 83, 862-869.

Dove, G. O. (2009). Beyond perceptual symbols: A call for representational pluralism. Cognition, 110, 412-431.

Falkenhainer, B., Forbus, K. D., \& Gentner, D. (1989). The structuremapping engine: Algorithm and examples. Artificial Intelligence, $41,1-63$.

Fernardino, L., Contant, L. L., Binder, J. R., Blindauer, K., Hiner, B., Spangler, K., \& Desai, R. H. (2013). Where is the action? Action sentence processing in Parkinson's disease. Neuropsychologia, 51, $1510-1517$.

Fischer, M. H., \& Zwaan, R. A. (2008). Embodied language: A review of the role of the motor system in language comprehension. Quarterly Journal of Experimental Psychology, 61, 825-850. doi:10.1080/ 17470210701623605

Frisson, S., \& Pickering, M. J. (2001). Figurative language processing in the Underspecification Model. Metaphor and Symbol, 16, 149-171.

Gallese, V., \& Lakoff, G. (2005). The brain's concepts: The role of the sensory-motor system in conceptual knowledge. Cognitive Neuropsychology, 22, 455-479. doi:10.1080/02643290442000310

Gentner, D. (1983). Structure-mapping: A theoretical framework for analogy. Cognitive Science, 7, 155-170. doi:10.1207/ s15516709 $\operatorname{cog} 0702 \_3$

Gentner, D. (1989). The mechanisms of analogical learning. In S. Vosniadou \& A. Ortony (Eds.), Similarity and analogical reasoning (pp. 199-241). Cambridge: Cambridge University Press.

Gentner, D., \& Bowdle, B. F. (2001). Convention, form, and figurative language processing. Metaphor and Symbol, 16, 223-247.

Gentner, D., \& Clement, C. (1988). Evidence for relational selectivity in the interpretation of analogy and metaphor. In G. H. Bower (Ed.), The psychology of learning and motivation: Advances in research and theory (Vol. 22, pp. 307-358). New York: Academic Press.

Gentner, D., \& France, I. M. (1988). The verb mutability effect: Studies of the combinatorial semantics of nouns and verbs. In S. L. Small, G. W. Cottrell, \& M. K. Tanenhaus (Eds.), Lexical ambiguity resolution: Perspectives from psycholinguistics, neuropsychology, and artificial intelligence (pp. 343-382). San Mateo: Morgan Kaufmann.

Gentner, D., \& Kurtz, K. J. (2005). Learning and using relational categories. In W. K. Ahn, R. L. Goldstone, B. C. Love, A. B. Markman, \& P. W. Wolff (Eds.), Categorization inside and outside the laboratory: Essays in honor of Douglas L. Medin (pp. 151-175). Washington, DC: American Psychological Association.

Gentner, D., \& Markman, A. B. (1997). Structure mapping in analogy and similarity. American Psychologist, 52, 45-56.

Gentner, D., \& Wolff, P. (1997). Alignment in the processing of metaphor. Journal of Memory and Language, 37, 331-355.

Gentner, D., \& Wolff, P. (2000). Metaphor and knowledge change. In E. Dietrich \& A. Markman (Eds.), Cognitive dynamics: Conceptual change in humans and machines (pp. 295-342). Mahwah: Erlbaum. 
Gentner, D., Bowdle, B., Wolff, P., \& Boronat, C. (2001). Metaphor is like analogy. In D. Gentner, K. J. Holyoak, \& B. N. Kokinov (Eds.), The analogical mind: Perspectives from cognitive science (pp. 199253). Cambridge: MIT Press.

Gibbs, R. W. (1994). The poetics of mind: Figurative thought, language, and understanding. Cambridge: Cambridge University Press.

Gibbs, R. W. (2006a). Embodiment and cognitive science. Cambridge: Cambridge University Press.

Gibbs, R. W. (2006b). Metaphor interpretation as embodied simulation. Mind and Language, 21, 434-458.

Gibbs, R. W., Costa Lima, P. L., \& Francozo, E. (2004). Metaphor is grounded in embodied experience. Journal of Pragmatics, 36, 1189-1210.

Giora, R. (1997). Understanding figurative and literal language: The graded salience hypothesis. Cognitive Linguistics, 8, 183-206.

Giora, R. (1999). On the priority of salient meanings: Studies of literal and figurative language. Journal of Pragmatics, 31, 919-929.

Giora, R. (2003). On our mind: Salience, context, and figurative language. New York: Oxford University Press.

Glenberg, A. M. (2010). Embodiment as a unifying perspective for psychology. Wiley Interdisciplinary Reviews: Cognitive Science, 1, 586-596. doi:10.1002/wcs.55

Glenberg, A. M., \& Kaschak, M. P. (2002). Grounding language in action. Psychonomic Bulletin \& Review, 9, 558-565. doi:10.3758/ BF03196313

Glucksberg, S. (2001). Understanding figurative language: From metaphors to idioms. Oxford: Oxford University Press.

Glucksberg, S., \& Keysar, B. (1990). Understanding metaphoric comparisons: Beyond similarity. Psychological Review, 97, 3-18. doi:10. 1037/0033-295X.97.1.3

Glucksberg, S., \& McGlone, M. S. (2001). Understanding figurative language: From metaphors to idioms. Oxford: Oxford University Press.

Glucksberg, S., McGlone, M. S., \& Manfredi, D. (1997). Property attribution in metaphor comprehension. Journal of Memory and Language, 36, 50-67.

Glucksberg, S., Newsome, M. R., \& Goldvarg, Y. (2001). Inhibition of the literal: Filtering metaphor-irrelevant information during metaphor comprehension. Metaphor and Symbol, 16, 277-298.

Hauk, O., Johnsrude, I., \& Pulvermüller, F. (2004). Somatotopic representation of action words in human motor and premotor cortex. Neuron, 41, 301-307. doi:10.1016/S0896-6273(03)00838-9

Heine, B. (1997). Cognitive foundations of grammar. Oxford: Oxford University Press.

Honeck, R. P., Kibler, C. T., \& Firment, M. J. (1987). Figurative language and psychological views of categorization: Two ships in the night? In R. E. Haskell (Ed.), Cognition and symbolic structures: The psychology of metaphoric transformation (pp. 103120). Norwood: Ablex.

Humphreys, G. F., Newling, K., Jennings, C., \& Gennari, S. P. (2013). Motion and actions in language: Semantic representations in occipito-temporal cortex. Brain and Language, 125, 94-105.

Johnson, A. T. (1996). Comprehension of metaphors and similes: A reaction time study. Metaphor and Symbolic Activity, 11, 145-159.

Johnson, M. G., \& Malgady, R. G. (1979). Some cognitive aspects of figurative language: Association and metaphor. Journal of Psycholinguistic Research, 8, 249-265.

Kable, J. W., Lease-Spellmeyer, J., \& Chatterjee, A. (2002). Neural substrates of action event knowledge. Journal of Cognitive Neuroscience, 14, 795-805.

Kable, J. W., Kan, I. P., Wilson, A., Thompson-Schill, S. L., \& Chatterjee, A. (2005). Conceptual representations of action in the lateral temporal cortex. Journal of Cognitive Neuroscience, 17, 1855-1870. doi:10.1162/089892905775008625

Kemmerer, D., Castillo, J. G., Talavage, T., Patterson, S., \& Wiley, C. (2008). Neuroanatomical distribution of five semantic components of verbs: Evidence from fMRI. Brain and Language, 107, 16-43. doi:10.1016/j.bandl.2007.09.003

Kövecses, Z. (1986). Metaphors of anger, pride, and love. Philadelphia: John Benjamins.

Kövecses, Z. (2005). Metaphor in culture: Universality and variation. Cambridge: Cambridge University Press.

Lacey, S., Stilla, R., \& Sathian, K. (2012). Metaphorically feeling: comprehending textural metaphors activates somatosensory cortex. Brain and Language, 120, 416-421.

Lakoff, G. (1987). Women, fire, and dangerous things. Chicago: University of Chicago Press.

Lakoff, G., \& Johnson, M. (1980). Metaphors we live by. Chicago: University of Chicago Press.

Lakoff, G., \& Johnson, M. (1999). Philosophy in the flesh: The embodied mind and its challenge to western thought. New York: Basic Books.

Lakoff, G., \& Turner, M. (1989). More than cool reason: A field guide to poetic metaphor. Chicago: University of Chicago Press.

Lebois, L. A. M., Wilson-Mendenhall, C. D., \& Barsalou, L. W. (2014). Are automatic conceptual cores the gold standard of semantic processing? The context-dependence of spatial meaning in grounded congruency effects. Cognitive Science. Advance online publication. . doi:10.1111/cogs.12174

Lehrer, A. (1990). Polysemy, conventionality, and the structure of the lexicon. Cognitive Linguistics, 1, 207-246.

Mahon, B. Z., \& Caramazza, A. (2008). A critical look at the embodied cognition hypothesis and a new proposal for grounding conceptual content. Journal of Physiology, 102, 59-70. doi:10.1016/j. jphysparis.2008.03.004

Markman, A. B., \& Gentner, D. (1993). Structural alignment during similarity comparisons. Cognitive Psychology, 25, 431-467.

Markman, A. B., \& Stilwell, C. H. (2001). Role-governed categories. Journal of Experimental and Theoretical Intelligence, 13, 329-358.

Mashal, N., Faust, M., Hendler, T., \& Jung-Beeman, M. (2007). An fMRI investigation of the neural correlates underlying the processing of novel metaphoric expressions. Brain and Language, 100, 115-126. doi:10.1016/j.bandl.2005.10.005

Meier, B. P., \& Robinson, M. D. (2004). Why the sunny side is up: Associations between affect and vertical position. Psychological Science, 15, 243-247.

Miller, G. A. (1979). Images and models, similes and metaphors. In A. Ortony (Ed.), Metaphor and thought (pp. 202-253). Cambridge: Cambridge University Press. doi:10.1017/ CBO9781139173865.019

Murphy, G. L. (1996). On metaphoric representation. Cognition, 60, 173204. doi:10.1016/0010-0277(96)00711-1

Murphy, G. L. (1997). Reasons to doubt the present evidence for metaphoric representation. Cognition, 62, 99-108. doi:10.1016/S00100277(96)00725-1

Obert, A., Gierski, F., Calmus, A., Portefaix, C., Declercq, C., Pierot, L., \& Caillies, S. (2014). Differential bilateral involvement of the parietal gyrus during predicative metaphor processing: An auditory fMRI study. Brain and Language, 137, 112-119.

Ortony, A. (1979). Beyond literal similarity. Psychological Review, 86, 161-180. doi:10.1037/0033-295X.86.3.161

Ortony, A. (1993). Metaphor and thought (2nd ed.). Cambridge: Cambridge University Press.

Pecher, D., \& Zwaan, R. A. (Eds.). (2005). Grounding cognition: The role of perception and action in memory, language, and thinking. Cambridge: Cambridge University Press.

Raposo, A., Moss, H. E., Stamatakis, E. A., \& Tyler, L. K. (2009). Modulation of motor and premotor cortices by actions, action words and action sentences. Neuropsychologia, 47, 388-396. doi:10.1016/ j.neuropsychologia.2008.09.017

Reilly, J., Westbury, C., Kean, J., \& Peelle, J. E. (2012). Arbitrary symbolism in natural language revisited: When word forms carry meaning. PLoS ONE, 7, e42286. doi:10.1371/journal.pone.0042286 
Richardson, D. C., Spivey, M. J., Barsalou, L. W., \& McRae, K. (2003). Spatial representations activated during real-time comprehension of verbs. Cognitive Science, 27, 767-780.

Rizzolatti, G., \& Craighero, L. (2004). The mirror-neuron system. Annual Review of Neuroscience, 27, 169-192. doi:10.1146/annurev.neuro. 27.070203.144230

Romero Lauro, L. J., Mattavelli, G., Papagno, C., \& Tettamanti, M. (2013). She runs, the road runs, my mind runs, bad blood runs between us: literal and figurative motion verbs: An fMRI study. NeuroImage, 83, 361-371.

Saygin, A., McCullough, S., Alac, M., \& Emmorey, K. (2010). Modulation of BOLD response in motion-sensitive lateral temporal cortex by real and fictive motion sentences. Journal of Cognitive Neuroscience, 22, 2480-2890.

Steen, G. J., Dorst, A. G., Herrmann, J. B., Kaal, A. A., Krennmayr, T., \& Pasma, T. (2010). A method for linguistic metaphor identification: From MIP to MIPVU. Philadelphia: Benjamins.

Sweetser, E. (1990). From etymology to pragmatics. Cambridge: Cambridge University Press.

Tettamanti, M., Buccino, G., Saccuman, M. C., Gallese, V., Danna, M., Scifo, P., ... Perani, D. (2005). Listening to action-related sentences activates fronto-parietal motor circuits. Journal of Cognitive Neuroscience, 17, 273-281. doi:10.1162/0898929053124965

Thibodeau, P. H., \& Boroditsky, L. (2011). Metaphors we think with: The role of metaphor in reasoning. PLoS ONE, 6, e16782. doi:10.1371/ journal.pone. 0016782

Tootell, R. B. H., Reppas, J. B., Kwong, K. K., Malach, R., Born, R. T., Brady, T. J., ... Belliveau, J. W. (1995). Functional analysis of human MT and related visual cortical areas using magnetic resonance imaging. Journal of Neuroscience, 15, 3215-3230.

Torreano, L. A., Cacciari, C., \& Glucksberg, S. (2005). When dogs can fly: Level of abstraction as a cue to metaphorical use of verbs. Metaphor and Symbol, 20, 259-274.

Traugott, E. C. (1978). On the expression of spatio-temporal relations in language. Universals of Human Language, 3, 369-400.
Tversky, A. (1977). Features of similarity. Psychological Review, 84, 327-352. doi:10.1037/0033-295X.84.4.327

Wallentin, M., Lund, T., Östergaard, S., Östergaard, L., \& Roepstorff, A. (2005a). Motion verb sentences activate left posterior middle temporal cortex despite static context. NeuroReport, 16, 649-652.

Wallentin, M., Östergaard, S., Lund, T. E., Östergaard, L., \& Roepstorff, A. (2005b). Concrete spatial language: see what I mean? Brain and Language, 92, 221-233.

Wallentin, M., Nielsen, A. H., Vuust, P., Dohn, A., Roepstorff, A., \& Lund, T. E. (2011). BOLD response to motion verbs in left posterior middle temporal gyrus during story comprehension. Brain and Language, 119, 221-225.

Watson, C. E., Cardillo, E. R., Ianni, G. R., \& Chatterjee, A. (2013). Action concepts in the brain: An activation likelihood estimation meta-analysis. Journal of Cognitive Neuroscience, 25, 1191-1205. doi:10.1162/jocn_a_00401

Wiemer-Hastings, K., \& Xu, X. (2005). Content differences for abstract and concrete concepts. Cognitive Science, 29, 719-736.

Wilson, M. (2002). Six views of embodied cognition. Psychonomic Bulletin \& Review, 9, 625-636. doi:10.3758/BF03196322

Wilson, N. L., \& Gibbs, R. W., Jr. (2007). Real and imagined body movement primes metaphor comprehension. Cognitive Science, 31, 721-731. doi:10.1080/15326900701399962

Wolff, P., \& Gentner, D. (2011). Structure-mapping in metaphor comprehension. Cognitive Science, 35, 1456-1488.

Zharikov, S., \& Gentner, D. (2002). Why do metaphors seem deeper than similes? In W. D. Gray \& C. Schunn (Eds.), Proceedings of the Twenty-Fourth Annual Conference of the Cognitive Science Society (pp. 976-981). Mahwah: Erlbaum.

Zwaan, R. A., \& Taylor, L. J. (2006). Seeing, acting, understanding: Motor resonance in language comprehension. Journal of Experimental Psychology: General, 135, 1-11. doi:10.1037/00963445.135 .1 .1 